\title{
Narrare. Rappresentare. La parola letteraria, lo schermo, la scena, a cura di Francesca Torchi
}

\section{Gabriella Bosco}

\section{Q OpenEdition}

1 Journals

\section{Edizione digitale}

URL: http://journals.openedition.org/studifrancesi/35503

DOI: 10.4000/studifrancesi.35503

ISSN: 2421-5856

\section{Editore}

Rosenberg \& Sellier

\section{Edizione cartacea}

Data di pubblicazione: 1 novembre 2005

Paginazione: 473

ISSN: 0039-2944

\section{Notizia bibliografica digitale}

Gabriella Bosco, «Narrare. Rappresentare. La parola letteraria, lo schermo, la scena, a cura di Francesca Torchi», Studi Francesi [Online], 146 (XLIX | II) | 2005, online dal 30 novembre 2015, consultato il 18 avril 2021. URL: http://journals.openedition.org/studifrancesi/35503 ; DOI: https://doi.org/10.4000/ studifrancesi.35503

Questo documento è stato generato automaticamente il 18 avril 2021.

\section{(c) (1)}

Studi Francesi è distribuita con Licenza Creative Commons Attribuzione - Non commerciale - Non opere derivate 4.0 Internazionale. 


\title{
Narrare. Rappresentare. La parola letteraria, lo schermo, la scena, a cura di Francesca Torchi
}

\author{
Gabriella Bosco
}

\section{NOTIZIA}

AA. VV., Narrare. Rappresentare. La parola letteraria, lo schermo, la scena, a cura di Francesca TORCHI, CLIEB, Bologna, 2003, pp. 184.

1 È questo il primo dei due volumi che raccolgono gli atti del convegno Narrare/ Rappresentare tenutosi a Parma e Bologna nell'ottobre del 2002. A cura di Francesca TORCHI e con una introduzione di Carmelina IMBRoscio, il libro propone una riflessione sul rapporto tra il testo narrativo e la scena, sia cinematografica che teatrale, per mettere in luce le dinamiche che intervengono nel passaggio da un genere all'altro, da un codice all'altro.

2 A monte del convegno e del volume, vi è un progetto di ricerca intitolato Da e verso la letteratura. Modalità di transfert (cui hanno partecipato le università di Bologna e Parma $\mathrm{e}$ studiosi delle università di Macerata e Palermo) che aveva avuto come prima tappa un altro convegno dedicato al rapporto tra il testo letterario e il sapere scientifico (Bologna, aprile 2002). Scopo della ricerca, nel suo insieme, era quello di individuare, nel rapporto tra testo letterario e espressioni altre dei vari ambiti del sapere, l'esistenza di scambi e interconnessioni, forieri di nuovi sensi e di nuove strategie espressive.

Qui, in due sezioni riservate rispettivamente alle trasposizioni cinematografiche e a quelle teatrali, si è indagato il rapporto tra una serie di testi e i loro adattamenti operati dagli scrittori stessi o da persone in stretta collaborazione con loro: quelle trasposizioni cioè il cui esito è meno soggetto alla personalità artistica autonoma dell'attante. 
Si passa così, nella prima sezione, dal rapporto tra la romanziera Louise de Vilmorin e il regista Max Ophuls (Cristina BRAGAGLIA), a quello tra commedia e sceneggiatura nel caso in cui - come avviene per East is East - l'autore è lo stesso, Ayub Khan Din (Elisa BUsSI), ai percorsi per così dire «a doppio senso», ovvero quelli in cui la versione cinematografica preesiste a quella narrativa o nasce contemporaneamente ad essa, come spesso avviene nell'ambito della fantascienza, laddove sono frequenti e fruttuosi i sodalizi, valga un esempio per tutti, quello tra Clarke e Kubrick (Gian Carlo CALCAGNO), o ancora a percorsi di tipo «inverso», quello cioè in cui il regista non utilizza testi già esistenti, ma chiede a uno scrittore di scrivergli una sceneggiatura per un film, come ha fatto Alain Resnais per il film Muriel, sollecitando Jean Cayrol (Luciana GRASSO). Un caso molto interessante di auto-trasposizione è quella operata da Samuel Beckett che adatta per la televisione alcune sue pièces. E, ancora, quello di François Truffaut che nel trarre ispirazione da Henry James per la sua Chambre verte, deve affrontare il non semplice problema di rendere sullo schermo le atmosfere rarefatte dello scrittore (Sandro vOLPE).

Nella seconda sezione, che indaga il rapporto tra testo narrativo e scena teatrale, è analizzato un interessante caso di opera narrativa che contiene al suo interno categorie teatrali e pittoriche, le Scènes de la vie privée di Honoré de Balzac (Mariolina BERTINI). È poi anche studiata, per completezza, l'eventualità in cui la sinergia fallisce, come avviene tra il romanzo Bruges-la-Morte e il film Le Mirage che ne è l'adattamento, benché l'autore di entrambi sia Georges Rodenbach (Barbara CANAPINI) Al contrario, estremamente riuscite sono le trasposizioni di testi narrativi per la scena operate da Luca Ronconi, i cui originali e liberi montaggi danno luogo a vere riscritture che al tempo stesso sono rivoluzionarie dal punto di vista dell'impianto drammatico (Claudio LONGHI). In qualche modo paragonabile al lavoro ronconiano, per finire, è un altro caso di trasposizione «interpretativa»: quella di Marguerite Duras che lavora sulla novella di James The Beast in the jungle (Elisabeth RALLO DITCHE). 